\title{
The Hunger Games
}

\author{
Thomas Pogge ${ }^{1,2}$
}

Accepted: 10 April 2016/Published online: 3 June 2016

(C) The Author(s) 2016. This article is published with open access at Springerlink.com

\begin{abstract}
Governments and their international agencies (FAO, World Bank) conceive of the eradication of hunger and poverty as a worthy wish that will eventually be realized through economic growth. They also make great cosmetic efforts to present as good-looking trend pictures as they can. Citizens ought to insist that the eradication of severe deprivations is a human-rights correlative duty that permits no avoidable delay. Academics ought to collaborate toward providing a systematic alternative monitoring of what progress has really been made against undernourishment and other poverty-related deprivations.
\end{abstract}

Keywords Food and Agriculture Organization · Human rights · Millennium Development Goals $\cdot$ Monitoring $\cdot$ Poverty $\cdot$ Progress

With the Millennium Development Goals (MDGs) and their recently anointed successors: the Sustainable Development Goals (SDGs), much more public attention has come to be paid to matters of poverty and development. It is widely understood now that humanity has been in possession, for some time, of the economic, technological and administrative means for the complete eradication of severe poverty on our planet. And the insistence that we must accomplish this task immediately is no longer the domain of leftist fringe groups and dedicated NGOs, but reaffirmed at the preeminent summits at which the leaders of our governments take care of the world's business. When the SDGs were adopted at the September 2015 meeting of the UN General Assembly in New York, the central commitment all governments joined hands in proclaiming was that we will "end poverty in all its forms everywhere" by 2030. With both the capacity and the political will clearly in evidence, we can rest assured that our governments will once and for all eradicate severe, life-threatening poverty from this planet within the next few years.

But, given the great importance of the issue, let us not rest assured too easily. Let us look at how well the world has actually done with regard to the MDGs that governments had adopted

Thomas Pogge

thomas.pogge@yale.edu; TPogge@uclan.ac.uk

1 Yale University, 203 Connecticut Hall, New Haven, CT 06520, USA

2 University of Central Lancashire, (UCLAN), UK 
in the year 2000. The MDGs set 18 targets for the year 2015, so we can look and see how close we have come to reaching them.

The most prominent of these targets, listed under the first MDG, envisioned that we would, between 1990 and 2015, halve extreme poverty and undernourishment. Tracking the former target, the World Bank reports that the prevalence of extreme poverty in the developing world has declined by two-thirds, and this already 3 years before the deadline; ${ }^{1}$ so in this regard we have achieved vastly more than promised. Tracking the latter target, the FAO reports that, during the MDG period, the prevalence of undernourishment in the developing world has declined from $23.3 \%$ in 1990-92 to an estimated $12.9 \%$ in 2014-16 (FAO, IFAD and WFP 2015,8 ). This is a $45 \%$ decline rather than the promised halving, but the shortfall seems too small to be alarming, too small to disturb our confidence that our governments are really hard at work toward implementing their ambitious plan to end poverty in all its forms everywhere.

But, given the great importance of the issue, let us conclude this essay with a brief examination of how the FAO tracks progress against undernourishment. This task is made easier by the fact that the FAO has in 2012 introduced a new method for identifying and counting the world's undernourished people and has provided a detailed explanation of this method (FAO, WFP and IFAD 2012, 50-56).

\section{The FAO Definition of Undernourishment}

Any method for tracking the extent of undernourishment consists of two components: a definition of undernourishment; and then measurement and estimation procedures for arriving at a count of the people suffering undernourishment so defined.

The FAO's operative definition is clear and straightforward:

"undernourishment" has been defined as an extreme form of food insecurity, arising when food energy availability is inadequate to cover even minimum needs for a sedentary lifestyle. ... the FAO indicator is designed to capture a clearly - and narrowly

- defined concept of undernourishment, namely a state of energy deprivation lasting over a year (FAO, WFP and IFAD 2012, 50).

The FAO definition of undernourishment thus has four elements. A person is to count as undernourished at some particular time just in case this time is part of a period of more than one year during which the food energy that is available to her - also referred to by the FAO as her dietary energy intake (FAO, WFP and IFAD 2012, 50) - is insufficient to cover even minimum needs for a sedentary lifestyle. Let us look more closely at these four elements of the FAO's operative definition.

The first element is that the FAO is focusing solely on dietary energy. This exclusive focus is problematic because human beings do not live on energy alone. If they did, then feeding people sufficient amounts of sugar could cheaply and elegantly solve the entire global undernourishment problem. Not even Coca Cola would claim that this is a solution. It is indisputable that human beings need various proteins, vitamins, minerals and other

\footnotetext{
${ }^{1}$ See http://iresearch.worldbank.org/PovcalNet (last visited December 25, 2015), reporting that the incidence of extreme poverty in the world's developing regions declined from $44.35 \%$ in 1990 to $14.88 \%$ in 2012 . The World Bank currently defines extreme poverty as affecting households whose income or consumption expenditure per person per day has less purchasing power than \$1.90 had in the United States in 2011.
} 
micronutrients to be adequately nourished, nay even to survive. Deficiencies in such nutrients are extremely widespread among poor people in less developed countries. Three povertyrelated such deficiencies, in particular, each cause hundreds of thousands of deaths annually. Vitamin-A deficiency substantially increases the annual death toll from measles, diarrhea, and malaria and also causes much vision impairment and blindness. Iron deficiency results in widespread anemia, which causes maternal and perinatal deaths and deaths in young children. Zinc deficiency contributes substantially to deaths from diarrhea, pneumonia, and malaria in children under five. Also important is iodine deficiency, which impedes intellectual development and physical growth. ${ }^{2}$ By ignoring such specific nutrient deficiencies in its definition, the FAO is failing to recognize as undernourished all those hundreds of millions of people who take in sufficient energy (calories) but do not get some of the specific nutrients essential to healthy survival.

The second element is that the FAO is focusing solely on dietary intake. This exclusive focus is problematic because not all the nutrients a person ingests are actually absorbed by her or his body. Many people in impoverished regions are infected with parasites that can easily consume as much as one-third of the nutrition they ingest. And others there suffer from diseases that impede the absorption of nutrients through the small intestine. By ignoring these common problems through its exclusive focus on intake, the FAO is further enlarging its undercount of the world's undernourished: the FAO is failing to recognize all those whose nutrient intake is adequate even while their nutrient absorption is not.

The third element of the FAO's operative definition of undernourishment is that, to count as undernourished, a person's energy intake must be "inadequate to cover even minimum needs for a sedentary lifestyle." This author and, I suspect, many of his readers are amateur experts on a sedentary lifestyle. I spend most of my days seated at my desk reading or typing away on my keyboard. But many poor people in the less developed countries do not, and cannot, indulge in such a lifestyle. The 1800 daily kilocalories that suffice to keep me going will not suffice to sustain a rickshaw driver whose income depends on transporting heavy loads on battered roads, often uphill. These $1800 \mathrm{kcal}$ will also not sustain a homemaker who must carry large jugs of water from a distant well, do the laundry in the river, collect firewood, grind cereals, participate in harvesting, and so on.

We can get a sense of what difference this makes from what we know about our own calorie consumption when we go to the gym. Exercise machines that have a display of calories burned usually tell me that I burn about $10 \mathrm{kcal}$ per minute or about $600 \mathrm{kcal}$ in a 60 -minute workout. Laborers working merely half as hard as I do in the gym, and this for merely 6 hours per day, thus burn an extra $1800 \mathrm{kcal}$ per day over and above the sedentary minimum. Living on an 1800-kcal diet deemed adequate by the FAO, such workers would starve and quickly become unable to hold down the job that pays for their food. But, by the FAO definition, such workers are classified as adequately nourished even while they consume only half the calories they need. By defining undernourishment in terms of the minimum requirements of a sedentary lifestyle, the FAO is then failing to recognize as undernourished all those millions who get enough food for a sedentary lifestyle but not enough for the work they actually do, and must do, to sustain themselves and their families.

The fourth element of the FAO's operative definition of undernourishment is that, to be deemed relevant, a nutritional deficit must last for "over a year." The FAO's count will therefore exclude people who are suffering seasonal hunger during wintertime and even people

$\overline{{ }^{2} \text { For all four common deficiencies }}$ see Caulfield et al. 2006. 
whose food supply is inadequate for eleven consecutive months. The FAO has an official justification for this decision, which is remarkable enough to deserve quoting in full:

the reference period should be long enough for the consequences of low food intake to be detrimental to health. Although there is no doubt that temporary food shortage may be stressful, the FAO indicator is based on a full year (FAO, WFP and IFAD 2012, 50).

Noteworthy here is the magnanimous concession that going hungry for less than a year may, just may, be stressful. But this concession is quickly superseded by the clear and resolute assurance that such under-one-year periods of hunger are certainly not detrimental to health.

This assurance is evidently radically incorrect. We know from the historical record of famines and hunger strikes that, with sufficient clean drinking water, human beings can survive without food for about 45-60 days at a low activity level. Even when they can get a little food here and there, people in famines often succumb in well under a year. In fact, many historical famines have lasted well under a year and have still killed tens of thousands of people. So, contrary to the FAO's assurance, periods of "temporary" hunger can be extremely "detrimental to health." Moreover, there are literally hundreds of studies documenting the health effects of even brief periods of undernourishment especially on children. Such temporary food shortage often permanently impedes mental and physical development, causing lifelong deficits in height, health and mental functioning (including stunting and wasting). It has even been documented - by tracking the children of women who were born just before the Great-LeapForward famine in China or the 1960 earthquake in Chile - that periods of severe undernourishment during childhood often damage the health of one's offspring born decades later. ${ }^{3}$

By recognizing only undernourishment lasting for over a year, the FAO is failing to recognize all those millions of people whose health is ruined by extended but shorter periods of inadequate nutrition. The FAO definition even excludes many of the 7 million human beings who die annually from inadequate nutrition, including some 3 million children. Many of these victims die after suddenly losing their access to adequate food as a result of some dramatic change in their circumstances, due to famine, for example, or due to the outbreak of war or civil war or due to an emergency affecting their household or community, such as a failed harvest, loss of employment, disease or accident. ${ }^{4}$ Those who die within a year never qualify as undernourished by the FAO's definition - even though they died from inadequate nutrition and nothing else.

As a final critical point about the FAO definition, let us ask whether there can be an undernourished rickshaw driver. We might be inclined to answer in the affirmative. But, according to the FAO, such a person is a biological impossibility. Given the third element of the FAO definition, this rickshaw driver would have to live on less than the minimum caloric requirements of a sedentary lifestyle; but, were he actually to do so, he would be dead in well under a year, thereby failing to satisfy the fourth element.

Having examined the FAO definition of undernourishment, we need not examine the FAO procedures for estimating the number of people suffering undernourishment so defined. The reason is that, even if the FAO procedures got the count precisely right, they would miss most actual undernourishment as any competent speaker of English would conceive of it. Guided by

\footnotetext{
${ }^{3}$ Sonia Bhalotra, Claudia Sanhueza and Yicho Wu, "Long-Term Economic Consequences of the 1960 Chile Earthquake" (2011), available at http://www.webmeets.com/files/papers/lacea-lames/2011/767/Paper_ 11Mayl2011.pdf (last visited April 24, 2016).

${ }^{4}$ For discussion of such examples, see Sen 1981.
} 
the FAO definition, these procedures ignore, by design, nutritional deficits other then energy. They ignore nutritional deficits due to impaired food absorption. They ignore nutritional deficits by people whose workload exceeds that of a sedentary lifestyle. And they ignore shorter-than-one-year nutritional deficits that cause death or ill health. Nutritional deficits of each of these four kinds are very widespread, and their inclusion could easily double or even treble the reported prevalence of undernourishment.

It could be said in defense of the FAO method that the FAO simply lacks the resources to drill down to the individual level: to study how the dietary intake of particular individuals relates to their dietary needs. All the FAO can do, given its resource constraints, is to make rough estimates about the total amounts of food consumed in the various countries and the distribution of this consumption over each country's residents.

I have three responses to this defense. First, if this is the situation, then the FAO should clearly say so rather than pretend that it can measure the number of undernourished people with four-digit precision. The FAO should clearly state that it is able to provide a rough estimate of the number of people who ingest fewer calories than needed for a sedentary lifestyle. It should provide confidence intervals for this estimate. And it should state clearly that its estimate excludes nutritional deficits other than energy, nutritional deficits due to impaired food absorption, nutritional deficits by people whose workload exceeds that of a sedentary lifestyle and shorter-than-one-year nutritional deficits that cause death or ill health. Above all, the FAO should clearly declare that, so far, no one has provided the resources that would be necessary to make reasonably accurate estimates of the extent, trend and geographical and demographic distribution of undernourishment in this world.

Second, the FAO should cite what credible relevant estimates are available even if it cannot integrate them into a single overall count. It should cite studies like, for example, that by the World Health Organization, which provides detailed data about the prevalence of irondeficiency anemia, which especially afflicts women during their reproductive years (ca. 259 million) and young children aged 6 to 59 months (ca. 134 million). ${ }^{5}$ This way the public can at least get a rough sense of what is being left out of the FAO count.

Finally, the FAO should seek funding for one or two thorough checks on its method to permit a rough appraisal of the magnitude of its error. These checks should be conducted by an independent research institute and involve taking a random sample in a randomly selected country or province, 2000 people perhaps, and then interviewing and examining these people for various kinds and symptoms of undernourishment. The resulting detailed snapshot could then be compared with whatever gross estimate the FAO has come up with for the same country or province, based on aggregate food consumption and distribution data. Such an independent check would give us at least a rough sense of the FAO's likely underestimation of undernourishment worldwide.

\section{The Political Background of the FAO's New Method}

In the preceding section, I hope to have shown not merely that the way the FAO tracks undernourishment is flawed, but that it is deeply flawed in obvious ways. The experts involved

\footnotetext{
${ }^{5}$ See World Health Organization, The Global Prevalence of Anemia in 2011, at https://www.k4health.org/sites/ default/files/who_global_prevalence_of_anaemia_in_2011.pdf (last accessed December 25, 2015), pp. 10-12.
} 
in formulating the FAO's new method know vastly more about human nutrition than I do, and it would be wholly incredible to claim that this is the best definition their collective expertise and wisdom could produce. So why did the FAO commit itself to such a plainly absurd method?

To understand this, we need to understand that progress against undernourishment has great political significance. A major argument for the grand neo-liberal globalization project is that it produces equitable economic growth: growth that lifts all boats, growth that lifts billions of human beings out of poverty. Making and winning this argument became especially important in the wake of the large-scale protests that overshadowed the launch of a new millennial round of trade negotiations at the WTO Ministerial Conference in Seattle in late November 1999. Before Seattle, the World Bank had painted a rather disturbing picture of the evolution of extreme poverty in the world: "The ongoing increase in population levels means that the absolute number of those living on $\$ 1$ per day or less continues to increase. The worldwide total rose from 1.2 billion in 1987 to 1.5 billion today and, if recent trends persist, will reach 1.9 billion by 2015" (World Bank 2000, 25). After Seattle, the picture brightened overnight, with World Bank President James Wolfensohn writing: "After increasing steadily over the past two centuries, since 1980 the total number of people living in poverty worldwide has fallen by an estimated 200 million - even as the world's population grew by 1.6 billion." 6 Today, the World Bank reports that in the 1987-99 period the number of people living in extreme poverty fell by 113 million $^{7}$ and that, throughout the 1990-2015 period, the decline in extreme poverty has been vastly faster than envisioned in the first $\mathrm{MDG}^{8}{ }^{8}$

Annoyingly, the FAO did not get the message and reported steadily rising numbers of undernourished people throughout the first decade of the 21 st century. During this time, those few who paid attention were thus treated to the rather odd spectacle of the World Bank reporting rapid declines in the number of people living in extreme poverty even while the FAO reported increases in the number of people going hungry. By the end of the decade, the World Bank's cumulative poverty decline since 1996 had grown to 600 million people while the FAO's cumulative undernourishment increase since 1996 had grown to 200 million people. Understanding the close relationship between extreme poverty and undernourishment, it is evident that these reported data series cannot both be right. It also became increasingly obvious that one of these two UN agencies would eventually have to back down.

Things came to a head when the FAO announced on 19 June 2009 that the number of undernourished people had, for the first time in human history, broken above 1 billion. ${ }^{9}$ The reason for this increase was a massive surge in world food prices - the

\footnotetext{
${ }^{6}$ James D. Wolfensohn, "Responding to the challenges of globalization: remarks to the G-20 finance ministers and central governors," Ottawa, 17 November 2001, cited in Nelson 2002, 26. These estimates appear to be drawn from World Bank (2002, p. 8).

${ }^{7}$ See http://iresearch.worldbank.org/PovcalNet (last visited December 25, 2015).

${ }^{8}$ For a critical perspective on the World Bank's successive methods for tracking extreme poverty, see Pogge 2010 , chapter 3 . I have not done a comprehensive study by any means, but I did notice that in the domain of the development goals changes of measurement method are quite frequent and that they regularly result in a betterlooking trend. If method replacements were unrelated to their impact on the trend, one would expect half of such replacements to result in a worse-looking trend. This is an interesting research topic that would be well worth a full investigation.

${ }^{9}$ FAO, “1.02 Billion People Hungry," 19 June 2009, at www.fao.org/news/story/en/item/20568/icode/ (last visited December 25, 2015).
} 
FAO's World Food Price Index had spiked from 89.6 in 2002 to 201.4 in $2008 .^{10}$ Such massive increases in the prices of basic foodstuffs always inflict the greatest pain upon the poor because they tend to spend $80-90 \%$ of their incomes on food and typically have the least opportunities to mobilize additional funds or to switch to cheaper foodstuffs. It is not surprising, then, that the massive price hikes triggered severe food shortages and food riots in dozens of less developed countries, including Bangladesh, Bolivia, Brazil, Burkina Faso, Cameroon, Egypt, Ethiopia, Haiti, India, Indonesia, Ivory Coast, Mauritania, Mexico, Morocco, Mozambique, Myanmar, Pakistan, Senegal, Somalia, South Africa, Sri Lanka, Tajikistan, Uzbekistan, Yemen. ${ }^{11}$

Shortly after the FAO made its widely publicized 1-billion announcement - which foreshadowed its subsequent "1 Billion Hungry" campaign, launched under the "We Are Mad As Hell" slogan ${ }^{12}$ - the world's governments decided to reform the Committee on World Food Security (CFS) and convened, in October 2009, a High Level Panel of Experts for Food Security and Nutrition (HLPE). ${ }^{13}$ Led by a steering committee of "15 world-renowned experts" from 15 different countries, ${ }^{14}$ this panel solicited and discussed a CFS expert report on the FAO's previous method and its possible improvement. ${ }^{15}$ The CFS then issued its own rather unspecific recommendations on the monitoring of undernourishment, ${ }^{16}$ which provided the needed cover for revising the FAO's method for estimating undernourishment still before 2015, the crucial year in which the expiration of the MDGs would occasion an overall assessment of the neo-liberal globalization project and the associated development efforts.

To be sure, no such cover would ordinarily be needed for an intergovernmental agency's decision to replace a method. In this case, however, cover was needed for two reasons. First, it is highly unusual, and plainly bad practice, to introduce a new measurement method, with plenty of hindsight, just barely before the end of a measurement period (in the 22nd year of the 25-year MDG exercise) - especially in a hotly political case, where the impact of globalization on the world's poor was heavily contested. Second, the switch to the new method led not to minor changes but to a dramatic reversal in the reported trend data, as the nearby table shows: it converted a $9 \%$ increase in the number of undernourished people into a $13 \%$ decrease and thereby brought the FAO's reporting into closer alignment with the World Bank's. It ensured, at least, that the officially reported undernourishment and extreme-poverty trends were now firmly headed in the same direction.

\footnotetext{
${ }^{10}$ See www.fao.org/worldfoodsituation/foodpricesindex/en/ (last visited December 25, 2015).

${ }^{11}$ See https://en.wikipedia.org/wiki/2007\%E2\%80\%9308_world_food_price_crisis (last visited December 25, 2015).

${ }^{12}$ See www.theguardian.com/katine/katine-chronicles-blog/2010/may/11/fao-blow-whistle-hunger (last visited December 25, 2015).

${ }^{13}$ See www.fao.org/fileadmin/user_upload/hlpe/hlpe_documents/HLPE_Key_elements_EN.pdf (last visited December 25, 2015).

${ }^{14}$ For the composition of the Panel, see www.fao.org/cfs/cfs-hlpe/hlpe-steering-committee/hlpe-stc/en/ (last visited December 25, 2015).

15 "CFS Round Table on Monitoring Food Security. Technical Background Paper," 31 August 2011, available at www.fao.org/fileadmin/templates/cfs_roundtable/Round_Table_technical_note.pdf (last visited December 25, 2015).

${ }^{16}$ CFS, Outcome of 'Roundtable to Review Methods Used to Estimate the Number of Hungry', at www.fao.org/ docrep/meeting/023/mc204E.pdf (last visited December 25, 2015).
} 
Millions of Undernourished in the Developing Regions Reported by FAO

\begin{tabular}{llll} 
Year & Before $2012^{17}$ & in $2012^{18}$ & in $2015^{19}$ \\
\hline $1990-92$ & 833 & 980 & 990.7 \\
$1995-97$ & 774 & 909 & \\
$2000-02$ & 821 & 905 & 908.4 \\
$2005-07$ & 839 & 870 & 926.9 \\
2009 & 1007 & 853 & 805.0 \\
2010 & 910 & 852 & 779.9 \\
$2014-16$ & & & \\
\hline
\end{tabular}

Remarkable about the new data is also that they show no impact of the massive surge in food prices during 2006-08. While the old numbers showed this surge causing a severe crisis among the world's poor, the new numbers show a steady decline in undernourishment during the relevant period, food riots in dozens of countries notwithstanding. The new hunger numbers persuasively vindicate the grand neo-liberal globalization project, which some had begun to question on the basis of the old hunger numbers: Washington-style globalization truly lifts all boats and, in particular, continuously lifts millions of poor people above the undernourishment and extreme-poverty thresholds. ${ }^{20}$

\section{The Political History of the Hunger Goal}

The idea that the world can and should eradicate hunger within a generation has been around since at least the middle of the 19th century and has been variously reiterated in the U.S. by Woodrow Wilson, Franklin Roosevelt, Harry Truman, Robert McNamara and others. The current version of this idea, which envisions that we undertake a first step of halving hunger by 2015, first came to social prominence at the 1996 World Food Summit in Rome. Some 186 governments signed on to this goal in their Summit Declaration with the words: "We pledge our political will and our common and national commitment to achieving food security for all and to an on-going effort to eradicate hunger in all countries, with an immediate view to reducing the number of undernourished people to half their present level no later than 2015."21

Reading this pledge, one might stumble over the strange use of the word "immediate." There is nothing immediate about a plan that allows 19 years for getting merely half of the work accomplished. To be sure, eradicating hunger is no picnic. But the same is true, even more so, of defeating the axis powers in the Second World War. So think of Franklin D. Roosevelt giving a speech in mid-1941, reciting the horrendous atrocities the Nazis and their

\footnotetext{
${ }^{17}$ FAO, WFP and IFAD 2012, Annex 2, p. 51; and FAO, "925 Million in Chronic Hunger Worldwide," at www. fao.org/news/story/en/item/45210/icode/ (last visited December 25, 2015). I have reduced the 2009 and 2010 numbers in the table to correct for the ca. 15 million undernourished people living outside the developing regions.

${ }^{18}$ FAO, WFP and IFAD 2012, p. 51.

${ }^{19}$ FAO, IFAD and WFP, p. 8.

${ }^{20}$ It was in these terms that the Economist magazine exuberantly celebrated the FAO's about-face in its gleeful article "Not a Billion After All," 10 October 2012, at www.economist.com/blogs/feastandfamine/2012/10/hunger (last visited December 25, 2015).

${ }^{21}$ Rome Declaration on World Food Security, at www.fao.org/docrep/003/w3613e/w3613e00.HTM (last visited December 25, 2015).
} 
allies were inflicting upon German citizens and the rest of Europe, and then pledging himself to an effort to end these horrors "with an immediate view" to achieving a $50 \%$ reduction by 1960. If Roosevelt had actually made such a pledge with a straight face, many would have thought he had gone mad, become morally deranged. And yet, when the world's governments made such a pledge regarding the fight against hunger, it was received with celebration and hearty congratulations all around.

One might want to justify this asymmetry of response by pointing out that the suffering caused by poverty and hunger isn't as bad as the suffering caused by Nazi Germany and its allies. But, in fact, poverty and undernourishment cause some 18 million painful deaths each year, some 450 million during the MDG period, ${ }^{22}$ while the entire Second World War caused "only" around 60 million deaths. ${ }^{23}$ So ending poverty and undernourishment isn't clearly less urgent or less important than ending the predations of the axis powers.

As another justification for the asymmetry, one might want to argue that overcoming poverty and hunger is much harder and more expensive than defeating the axis. But this, too, is untrue. At the height of the Second World War, the belligerent powers spent about half of their Gross National Incomes on fighting the war - the Russians, the British and even the U.S. did so. Overcoming poverty and hunger, by contrast, would require only around $2 \%$ of the rich countries' Gross National Incomes and could be done relatively quickly. This latter fight would also be much easier because it would not really be a fight. Nobody would be opposing us; no one would stand up to defend hunger and poverty.

So the grand promise of 1996 was really remarkably unaspiring. With so many millions of lives at stake, the assembled governments should have committed themselves to a much more ambitious effort. This assessment is greatly supported by the fact that they were, during the 1990s, reaping substantial economic rewards from the end of the Cold War, which enabled the high-income countries to reduce their military spending by about $2 \%$ of gross national income (ca. $\$ 400$ billion per annum). How much of this peace dividend did the high-income countries devote to promoting poverty eradication and economic development in the poorer countries? Did they, with their Peace Dividend, at least finally fulfill their old pledge from the 1970s to increase their official development assistance to $0.7 \%$ of their gross national incomes? Sadly, no. The high-income countries sharply reduced their official development assistance during the 1990 s from $0.32 \%$ down to $0.22 \%$ of their gross national incomes - presumably on the calculation that, with the demise of the Soviet Union, the less developed countries had no choice but to accept Western leadership.

Back to the World Food Summit pledge of 1996. This pledge committed the world's governments to reducing, no later than 2015, the number of undernourished people to half the present (1996) level. At the time this pledge was made, the 1996 number of undernourished was not yet available, but the FAO subsequently put it at or close to 790 million. ${ }^{24}$ The pledge thus was that in 2015 there would be no more than $\mathbf{3 9 5}$ million undernourished human beings. The governments making this pledge may have assumed that ordinary economic growth

\footnotetext{
${ }^{22}$ This estimate is based on the WHO's classification of deaths by cause, counting as poverty-related all those death causes that are essentially confined to the poor countries. When almost no one dies of diarrhea in the affluent countries and millions die from diarrhea in poor countries, then I assume that diarrhea is a poverty-related cause and diarrhea deaths are poverty-related. I use the WHO's data for 2004 as this year is roughly in the middle of the MDG period. See WHO 2008.

${ }^{23}$ See https://en.wikipedia.org/wiki/World_War_II_casualties (last visited December 25, 2015). Expressed in percentage terms, the Second World War killed off just over $3 \%$ of humanity within 6 years while severe poverty and undernourishment have been killing off just under $3 \%$ of humanity every decade.

${ }^{24}$ FAO 1999, 4 and back cover. This was the FAO's first SOFI report.
} 
would produce the $3.6 \%$ annual decline needed to reach the target and that they would therefore not actually have to make any special efforts toward reducing undernourishment. If so, they were sorely mistaken. The year 1996 turned out to be an all-time low in the number of undernourished people, ${ }^{25}$ and at the dawn of the new millennium the FAO found itself compelled to announce: "This year we must report that progress has virtually ground to a halt. Our latest estimates, based on data from the years 1998-2000, put the number of undernourished people in the world at 840 million, of whom 799 million live in developing countries. That figure represents a decrease of barely 2.5 million per year over the 8 years since 1990-92, the period used as the starting point for the drive launched at the World Food Summit." ${ }^{26}$ Noteworthy here is not merely the massive 50-million rise since 1996 in the reported number of undernourished people, but also the effort to conceal this increase by misrepresenting the fact that the joint Declaration concluding the World Food Summit in Rome had very explicitly designated 1996 as the base year in terms of which the target of halving undernourishment was defined.

Avoidance of the especially challenging base year of 1996 was also in evidence when the world's governments convened once again in September of the year 2000, in the UN General Assembly, for purposes of adopting the Millennium Declaration. In its Articles 19-23, this Declaration formulates various development goals - including once more the halving of hunger - but defines these reductions against the baseline of "current rates," that is, with a new base year of $2000 .{ }^{27}$ Instead of simply reiterating the goal announced at the 1996 World Food Summit, the Millennium Declaration thus formulates a new goal, albeit with the old language of halving hunger by 2015 . This goal is new not merely by shifting the base year from 1996 to 2000. It is new also by switching from halving the number of hungry people to halving "the proportion of the world's people ... who suffer from hunger."

Now, "proportion" means the same as "ratio" or "percentage." So we are now monitoring the evolution of undernourishment as a fraction that has the number of undernourished people in the numerator and the world's population in the denominator. What difference does this make? Well, one can halve a fraction either by halving the number in the numerator or by doubling the number in the denominator or by some mixed strategy. In the case before us, the denominator - the world's population - is growing nicely on its own, thereby continuously shrinking the value of the fraction. So, with this new formulation, population growth in the denominator is doing some of the work of reducing hunger, and therefore less work remains to be done in the numerator. If world population grows by $20 \%$ in the 15 -year plan period, for example, to $120 \%$ of what it was in the year 2000, then the number of undernourished people needs to fall by only $40 \%$, to $60 \%$ of what it was in the year 2000, to achieve the promised halving. Thus, by reformulating their commitment in the Millennium Declaration, governments substantially diluted their promise even while retaining the old language of halving undernourishment.

Let me be very clear that I do not care whether governments state their hunger promise in terms of a number or in terms of a proportion. What I object to is the surreptitious switch, which constitutes an illicit shifting of the goal posts. Governments kept the headline formulation of the goal - "we will halve poverty and undernourishment by 2015 " - but they lowered the bar so as to make this goal more easily achievable.

\footnotetext{
${ }^{25}$ Of course, only until the new method for tracking undernourishment was introduced in 2012.

${ }^{26}$ See www.fao.org/docrep/005/y7352e/y7352e02.htm\#P1_8 (last visited December 25, 2015).

${ }^{27}$ United Nations Millennium Declaration, at www.un.org/millennium/declaration/ares552e.htm (last visited December 25, 2015).
} 
We can illustrate the point with actual numbers. At the time the Millennium Declaration was adopted, the incidence of undernourishment was estimated to be around 840 million out of a world population of 6,321 million; this is $13.29 \%$. Halving this proportion by 2015 means ensuring that, by then, no more than $6.65 \%$ of humanity is undernourished. The human population is 7.4 billion at the end of 2015, so the Millennium Declaration effectively promises that the number of undernourished people in the year 2015 will not exceed 492 million. By switching base year and by aiming to halve a proportion rather than a number, our governments added nearly 100 million to the number of people whose undernourishment in the year 2015 was to be considered acceptable.

Soon after the UN General Assembly had officially adopted the Millennium Declaration, the UN leadership re-issued the promises contained therein as the Millennium Development Goals. This was presented and widely reported and understood to be just a reiteration of the commitments that the UN General Assembly had officially espoused. In fact, however, the commitments were revised yet again - by UN Secretary General Kofi Annan and his closest advisers. They made two important changes.

First, they confined all the goals to "the developing world," so that the fraction to be monitored was now that of: number of undernourished people in the developing world divided by total number of people in the developing world. Undernourished people outside the developing world were simply left out of account, even though their number was estimated to exceed 20 million. By confining the numerical exercise to the less developed countries, the promised halving of undernourishment becomes easier once again. Because the population of the less developed countries grows faster than the population of the world at large, even more work is now done in the denominator and even less work therefore remains to be done in the numerator, where we are actually reducing the number of undernourished people.

The second important change made by the UN leadership was yet another change in the base year. They backdated, for all the goals, the base year in which the MDG effort was to commence to the year 1990. This backdating of the beginning of the plan period has two important consequences. On the one hand, it lengthens the time period in which the population of the less developed countries is growing, thereby ensuring that even more work is done in the denominator. On the other hand, this backdating also makes it possible to count China's successes in hunger and poverty reduction during the 1990s toward the fulfillment of the promises made in the year 2000. Apparently someone thought that it would be a shame for China's great efforts in the 1990 s to go to waste - surely these should be counted as contributing to the fulfillment of the commitments that the world's governments made at the dawn of the new millennium.

This brave decision to fulfill promises made in the year 2000 partly with China's achievements of the 1990s had some comical effects - for example, that Kofi Annan was able to announce in his very first progress report that the world's most populous region, East Asia and the Pacific, had fully achieved the target of halving extreme poverty already in 1999, a full year before this target had even been even formulated, adopted and announced. ${ }^{28}$ It is noteworthy by the way that, unlike the subsequent reports, this first progress report misrepresents itself as reporting on progress in regard to the Millennium Declaration. As the content of the report makes clear, however, it is in fact a report in regard to the Millennium Development Goals.

\footnotetext{
${ }^{28}$ See United Nations, Implementation of the United Nations Millennium Declaration: Report of the SecretaryGeneral, A/57/270, 31 July 2002, at www.un.org/millenniumgoals/sgreport2002.pdf?OpenElement (last visited December 25, 2015), p. 8.
} 
This confusion seems to be an effort to make it appear as though the MDGs are what the UN General Assembly had adopted as part of the Millennium Declaration. This, however, is clearly not so. The MDGs measure progress against hunger and extreme poverty relative to the baseline of the year 1990 and limited to "the population of the developing regions." The Millennium Declaration, by contrast, measures progress against hunger and extreme poverty relative to the baseline of the "current" year 2000 and includes all of humankind within its scope. $^{29}$

Let me once more illustrate the effect of these further shifts with actual figures. The official 1990 number of chronically undernourished people in the developing countries was 843 million. This is $19.83 \%$ of the 4,252-million population of the less developed countries in 1990. The MDG target of halving hunger implies then that the number of hungry people in the developing world should, in 2015, not exceed $9.92 \%$ of 6,045 million, that is, 600 million and this ceiling is no longer including hungry people outside the developing world whose number the MDGs leave completely unconstrained.

The successive reformulations of the promise to halve undernourishment by 2015 have thus dramatically diluted its meaning. In the initial World Food Summit interpretation, this promise required that there be no more than 395 million undernourished people worldwide in 2015 . The final MDG version of the promise for the year 2015 permitted 600 million undernourished people just in the developing world while placing no limit on the number of undernourished people elsewhere.

On top of this came the FAO's new method, introduced in 2012, which, by raising the 1990 baseline number of undernourished people in the developing world by $17.5 \%$ to 990.7 million, ${ }^{30}$ correspondingly raised also the permissible year-2015 number of undernourished people in the developing countries by the same percentage to $\mathbf{7 0 5}$ million.

Recall, finally, that when the FAO checks whether the world has achieved the 2015 target of 705 million undernourished people in the developing world, it uses an absurdly narrow definition of undernourishment, counting only those people who, for over a year, ingest less energy than is needed to meet the minimum requirements of a sedentary lifestyle.

In concluding this section, let me briefly show how the various goalpost shifts that our governments and their intergovernmental agencies have introduced have affected their measured performance with regard to their promise to halve undernourishment by 2015 .

Going with the World Food Summit version of the promise and the initial method for counting the undernourished, we find that, far from achieving a halving of undernourishment, or even any reduction, governments have allowed undernourishment to increase: by $7 \%$ in the 1996-2000 period, by $30 \%$ during 1996-2009 and by 17\% during 1996-2010.

Going with the Millennium Declaration version of the promise and the initial measurement method, we find that the proportion of the world's people suffering from undernourishment remained roughly constant over the 2000-2010 period: the number of undernourished increased, but barely faster than the human population. In the year 2000, undernourishment was

\footnotetext{
${ }^{29}$ Both the Millennium Declaration and the first MDG speak of the proportion of people suffering from hunger rather than undernourishment. This makes it even more inappropriate for the FAO to track progress in terms of its extremely restrictive definition of undernourishment. It is evidently a gross violation of ordinary language to claim that a person cannot be suffering from hunger unless her dietary energy intake is insufficient for a sedentary lifestyle for over a year.

${ }^{30}$ FAO, IFAD and WFP 2015, 8. When the method had been first introduced, 980 million was given as the 1990-92 number of undernourished in the developing world. See FAO, WFP and IFAD 2012, 9.
} 
840 out of 6239 million or $13.27 \%$. In the year 2010, undernourishment was 925 million out of 6955 million or $13.30 \%$.

Going with the MDG version of the promise and the initial measurement method, we find that there has been some progress. In the developing world, the proportion of people suffering from undernourishment has fallen from $19.82 \%$ (843 out of 4252 million) in 1990 to $15.94 \%$ (910 out of 5709 million) in 2010 . This is a $19.6 \%$ decline in the proportion - much less embarrassing than the two preceding presentations, but still far off-course as far as the promised halving is concerned. After four-fifth of the plan period has elapsed, the proportion ought to be down by about $40 \%$.

When we combine the MDG version of the halving promise with the new measurement method, however, we can finally report that the fight against hunger is right on track. In the developing world, the proportion of people suffering from undernourishment has fallen from $23.3 \%$ (990.7 out of 4252 million) in 1990 to $14.1 \%$ (805 out of 5709 million) in 2010. This is exactly the $40 \%$ decline needed in order to be on track toward success in 2015 .

Unfortunately, the FAO's new method did not deliver as impressive results after its introduction as it had produced in its retroactive application. The FAO is currently estimating that its final tally for the end of 2015 will come in at 779.9 million undernourished people in the developing countries, equivalent to $12.9 \%$ of their total population (FAO, IFAD and WFP $2015,8)$. This would constitute a $45 \%$ reduction in the proportion of undernourished people (reported as $23.3 \%$ in 1990). This will be considered a tolerable shortfall from the promised halving, even though it does look a bit embarrassing next to the fabulous overachievement that the World Bank has been reporting from the extreme-poverty front.

Faced with widespread and persistent undernourishment in the world, one can do two very different things. One can undertake efforts toward ensuring that as many human beings as possible gain secure access to an adequate food supply. Or one can undertake efforts to put as positive a spin on the facts as one's creativity, one's moral principles and these facts will allow. I have here discussed solely the latter efforts and shown how immensely effective they have been. They have moved us from the $30 \%$ increase in undernourishment (from 790 million in 1996 to 1023 million in 2009) that inspired the "1 Billion Hungry" campaign to a $40 \%$ decrease in undernourishment (from $23.3 \%$ in $1990-92$ to $14.1 \%$ in $2010-12$ ) - without changing the situation of even one single undernourished person.

\section{Lessons to be Learned}

To be successful, governments and politicians in power must appear to care about the issues the citizens of their countries care about and must appear to be effective in addressing these issues. Citizens care about severe poverty and hunger, both at home and abroad. Therefore governments and politicians in power have an interest in expressing support for the struggle against poverty and hunger. Development goals, food summits, climate agreements - these are, also, political spectacles: put on as propaganda, as public relations. They give governments a very public way of showing that they care as much as we citizens do, and perhaps even more so, seeing the loftiness of their commitment to end poverty in all its forms once and for all. Through this concerted display, governments produce political allegiance to themselves - and complacency: when nearly all governments agree to something, then it's a done deal and we citizens need no longer worry about it or agitate for it. And through this joint performance governments also divert attention away from the structural causes for the persistence of severe 
poverty, from the powerful centrifugal forces that the present organization of the global trading and financial systems produces. Led to celebrate the great paper advances of the SDGs and the Paris climate agreement, we citizens are led to overlook the very real fact that 2015 also saw the richest $1 \%$ of humanity expand its share of global private wealth to over half $(50.4 \%){ }^{31}$ The poorer half of humanity, meanwhile, was squeezed down to a mere $0.6 \%$ of global private wealth, as much as is owned by the world's richest 62 billionaires. $^{32}$

Governments and politicians in power must not merely appear to care. To be successful, they must also appear to be effective in addressing the issues their citizens care about. They therefore have an interest in trying to support the appearance that they are effective contributors to the fight against hunger and poverty. This appearance is most easily maintained when the struggle can be made to appear successful. Such an appearance of success can be achieved through real success: through substantial reductions in severe poverty and hunger. But it can also be achieved, and at much lower cost, through creative accounting and clever exposition. As the saying, popularized by Mark Twain, has it: there are lies, damn lies and then there are statistics. $^{33}$

Statistics can be used to mislead without lying, and they have the further advantage of being complicated. The limited debunking exercise I have performed above is, admittedly, not beyond the reach of a dedicated college student, but it does go well beyond what ordinary citizens of affluent countries are suspicious and committed enough to wade through especially when they know how hard it would be to get a hearing for the results of their work among their compatriots. This is decidedly not a story that mainstream media would care and dare to pick up.

Intergovernmental agencies such as the UN and its sub-organizations, including the FAO and the World Bank, are politically vulnerable and exposed. Governments appoint and then reappoint or replace their top officials. Governments finance their budgets - partly through regular assessed contributions and partly through ad hoc payments in support of particular programs and initiatives. ${ }^{34}$ And governments also influence the success or failure of those agencies in countless other ways. Officials in these intergovernmental agencies therefore have a personal and professional interest in being on good terms with national governments and politicians in power, especially with those of the most powerful states.

To surmise that this interest has an impact, one does not need to postulate some nefarious conspiracy where some U.S. State Department official phones the FAO's Director-General to demand a better-looking hunger trend. Nor does one need to postulate corruption or immorality within the FAO. The effect can come about in a benign way also, like this. FAO officials understand how much their genuinely important work depends on the willing support of the more powerful governments. They also understand that it matters to these governments that their neo-liberal globalization project should be perceived as equitable and successful.

\footnotetext{
${ }^{31}$ Credit Suisse, Global Wealth Report 2015, at https://www.credit-suisse.com/ch/en/about-us/research/researchinstitute/publications.html (last visited December 25, 2015), p. 19.

${ }^{32}$ Oxfam, 62 People Own the Same as Half the World, Reveals Oxfam Davos Report, available at https:/www. oxfam.org/en/pressroom/pressreleases/2016-01-18/62-people-own-same-half-world-reveals-oxfam-davos-report (last visited February 10, 2016).

33 The origin of the saying is obscure. See www.york.ac.uk/depts/maths/histstat/lies.htm (last visited December $25,2015)$.

34 The FAO receives fully $59 \%$ of its funding in the form of such ad hoc support. See www.fao.org/partnerships/ resource-partners/en/ (last visited December 25, 2015). And even regular assessed contributions cannot be counted upon: the U.S. has withdrawn twice (1984 and 2011) from UNESCO in protest, for example, thereby cutting that agency's budget by about one quarter.
} 
Therefore, in order not to endanger the FAO's good work, they take care not to antagonize powerful governments; and, if they find that they have given offence (as the FAO found in the wake of its "1 Billion Hungry" campaign), then they try to make amends.

The first lesson is straightforward. If we want to have accurate information about the extent, trend and distribution of deprivations such as undernourishment, then we must not entrust the task of gathering, processing and presenting this information to such politically exposed and vulnerable intergovernmental agencies. Let these agencies lead the effort to eradicate hunger and severe poverty, but let us not also put them in charge of assessing this effort. This assessment function can be far more reliably performed by an independent network of reputable academic experts, proceeding with vigorous peer review in an objective and transparent manner.

Academics can really make a meaningful contribution to the fight against poverty by participating in this sort of assessment effort that draws on their special training and academic virtues. We should convene the best academic thinkers on poverty from the relevant disciplines and from a broad range of countries, and should ask them to agree, step-by-step, in an open and transparent process, on a definition of poverty, undernourishment, etc., and on plausible and feasible measurement procedures. Once agreed upon, no such measurement method should be revised for any reason during the measurement period. It can of course be criticized and be revised on the basis of such criticism; but the implementation of any such revision should wait until the next measurement period so as to make evident that there are no ulterior motives in play. We have superb academics who have excellent reputations at risk and who would do a great job in constructing, together, a solid measurement method in a transparent and politically independent way - converging, one would hope, upon something more nuanced than the FAO's simple binary classification: tracking undernourishment at the population level must be sensitive at least to the severity of individual nutritional deficits, which depends on their nature, magnitude and duration.

The proposed academic network should also be entrusted with organizing and supervising the associated data collection to ensure that it follows the agreed-upon method as closely as feasible. Once all this is in place, the world will be able, for the first time, to have confidence in the official reports about the extent, trend and geographical and demographic distribution of undernourishment.

Governments will not easily give up monopoly control over the official development data, especially after they have, by proclaiming a plethora of development goals, conferred some political prominence upon these data. So I do not expect that governments would be prepared to transfer the relevant assessment funding from their own intergovernmental agencies to an objective and independent academic network. It is entirely possible, however, that we academics build an international and interdisciplinary research network that systematically produces an alternative dataset - a comprehensive second opinion, if you like - on the nature, prevalence, severity, trends and distribution of deprivations worldwide. ${ }^{35}$ This is something that, with the help of ordinary research funding, we can organize ourselves to do well, and it is something that we absolutely owe to the world's poor.

The proposed network would still have to contend with governments that are determined to control the data about their own country. Currently, when such a government is powerful enough, it can insist that its own data be accepted by the relevant intergovernmental agency or

\footnotetext{
${ }^{35}$ The Seattle-based Institute for Health Metrics and Evaluation constitutes a partial model of how such a network might function.
} 
can at least demand to "collaborate" in and thereby influence the collection and processing of its national data. (Not all national statistical offices are wholly objective and free from political influence.) The proposed network may be able to do better by rigorously documenting any constraints on or interference with its work - something that intergovernmental agencies are rarely in a position to do. Such a practice of documentation would work as a deterrent against interference and would also give data users a sense of the varying quality and likely bias of the component data.

Proceeding now to the second lesson. We should expect, and be vigilant against, government commitments that look much more ambitious than they really are. Examples of this are commitments that governments can deflate after the fact by revising, with the benefit of hindsight, their meaning and measurement, as they have done with their commitments to halve poverty and undernourishment by 2015 .

But the problem goes deeper than this insofar as the entire practice of historical benchmarking easily makes it appear as though all progress is governmental achievement even while much of the improvement in the conditions of the world's poor is simply the effect of ordinary economic growth. Real global per capita income is said to have grown at 2 to $2.5 \%$ annually in recent decades, amounting to an increase of roughly $70 \%$ over any 25 -year period. ${ }^{36}$ In fact, this was roughly the increase in real global per capita income during the 1990-2015 MDG period. With such a quarter century of growth, it is to be expected, then, that incomes in the poorer percentiles of humanity will end up about $70 \%$ higher. And this will naturally raise many of these poorer percentiles above any stationary extreme poverty line and to an income level that suffices for secure access to adequate nutrition. To say that our governments' MDG exercise has "lifted" all these people out of poverty is pure nonsense. In fact, on the contrary, even more people would have escaped extreme poverty if our governments had ensured a more equitable distribution of the global economic growth of the last 25 years rather than channeling a disproportionately large share of it to the top percentiles of the global income and wealth hierarchy.

We have seen that, by assessing their performance diachronically (by comparison against a historical benchmark), our governments are massively biasing this assessment toward success. Effortless progress is all but assured if we compare the condition of the poor with their condition in the much poorer world economy of 15 or 25 years ago. (It is all the more distressing, then, that, according to the FAO's old method, the number of undernourished rose by $21 \%$ in the $1996-2009$ period, from 843 to 1023 million.)

Such diachronic assessments also involve an even deeper and more pernicious distortion. They suggest, falsely, that present deprivations are somehow rendered morally more acceptable by the fact that like deprivations were even more widespread and severe in the past. To appreciate this monumental moral error, consider the example of slavery in the U.S. antebellum South. Imagine a defender of slavery in 1845 describing all the ways in which slavery had become less cruel during the preceding 20 years: slaves were not worked as hard as had been customary in 1820, floggings and rapes of slaves had become less brutal and less frequent, and it had also become less common for slave families to be split apart through sales to different buyers. Would all this progress justify or excuse, in any way, the continuation of the practice of slavery? Evidently, it would not. The fact that slavery had been even worse in

\footnotetext{
${ }^{36}$ Max Roser, "Real GDP per capita around the world (PPP adjusted), since 1600," downloadable data, at http:// ourworldindata.org/data/growth-and-distribution-of-prosperity/gdp-growth-over-the-last-centuries/ (last visited December 25, 2015).
} 
earlier times is morally irrelevant. The morally relevant comparison is not with what had been actual 25 years earlier, but with what was possible right then, in 1845. If it was possible to abolish slavery in 1845, then slavery ought to have been abolished then.

We should make the analogous response to the persistence of widespread undernourishment and other poverty-related deprivations: they are avoidable, their continuation is a grave injustice, and they ought to be eradicated from our world as quickly and thoroughly as is humanly possible. The fact that hunger and poverty were even worse in earlier years should not be allowed to detract from this moral imperative. In both cases, the morally relevant comparison is not the diachronic one with an earlier state of the world, but the synchronic one with what is presently possible. The abolition of slavery was possible in 1845 , and so it should have been abolished then. The eradication of severe poverty worldwide is possible today, so we must eradicate it as fast as we possibly can.

Once we have the synchronic comparison firmly in view, we can apply a different kind of historical comparison. We can ask how much of the severe poverty and undernourishment extant in different periods of human history was avoidable at those times. Unlike the historical comparison that the MDGs and SDGs seek to encourage, this historical comparison comes out firmly against our present generation. Never in human history has severe poverty been as easily and as completely eradicable as in the present period. That we continue to perpetuate it through national and supranational institutional arrangements massively skewed in favor of the rich manifests a great moral failing of our generation, of governments and citizens alike.

Let me relate the second lesson to the contrast between goals and rights. The language of goals invites a diachronic, incremental approach: we have a certain distance to traverse, and so we set off in the direction of our destination and approach it step-by-step. This image is wholly out of place when rights are at issue. When we recognize a human right not to be enslaved, then we must not make a 25-year plan aiming to halve the number of slaves or aiming to make slavery half as cruel. When we recognize a human right not to be exterminated, then we must not make a 25-year plan to reduce the Nazi killing rate to half its present level. When we recognize a human right not to be subjected to economic institutions under which many people foreseeably and avoidably cannot meet their basic needs, then we must not make a 25 -year plan to halve these deprivations but must at once initiate the necessary institutional reforms. Our governments have, of course, recognized such a human right many times, most prominently perhaps in their International Covenant on Social, Economic and Cultural Rights adopted in 1966 and legally binding since 1976 - which postulates "the fundamental right of everyone to be free from hunger" (Article 11(2)).

Conversely, if we do regard the eradication of severe poverty and undernourishment as a goal to be slowly approached over many decades, thereby accepting hundreds of millions of poverty-related deaths in the interim, then we are in effect denying that there is a human right to life, a human right to an adequate standard of living.

In a way, our response has been even worse than that. The concept of a goal implies some definite agent whose goal it is. And it implies that this agent has a reasonably clear idea about the steps she will take to achieve the goal and also has both the commitment and the means necessary to take these steps. Many people before John F. Kennedy had expressed the desire that human beings should visit the moon. But for them such a visit was not a goal because they either had no idea how to get there or else lacked the necessary means for organizing such a journey. Even if such people declared a human visit to the moon to be their goal, it would be more accurately described as their wish. Kennedy, however, transformed this wish into a goal. He had a plan, and he was willing and able to mobilize the means this plan called for. 
Given this distinction between goals and wishes, I think it would be more appropriate to speak of the Millennium Development Wishes. Governments publicly agreed that it would be a good thing if a certain set of propositions were to come true by 2015. Let hunger be half as widespread as it was in 1990 (and let there be love and peace as well!). But they did not agree on a division of labor and of responsibilities toward making these propositions true. The agreement left entirely unspecified who was to do what. So, when we fell behind, badly, on undernourishment and other fronts, there was no authoritative way of identifying the party or parties required to make additional efforts to get us back on target. This complete exclusion of specific responsibilities from the agreement made it easy for governments to sign on, because they were committing themselves to nothing in particular: should some of the agreed wishes remain unfulfilled, each government would always be able to explain this by lamenting others' insufficient exertions. And so it actually happened when progress stalled: governments looked encouragingly at one another with the sharable prompt that "something ought to be done."37

Now in this game of blame shifting, the developed West has the advantage of possessing the loudest and savviest media, and it used this advantage to propagate the notion that each country should be in charge of achieving the MDGs within its own territory. We are, to use another example, to reduce by two thirds the global rate of children dying before the age of 5; so each country should reduce its under- 5 mortality rate by two thirds. If the world is underperforming, then the governments of the underperforming countries are to blame.

But this division of labor is evidently hugely unfair, because it saddles the poorest, least capable countries with the largest responsibilities: the poorer and hence less capable a country is, the larger is its task. Extremely poor countries with very high birth rates, such as Angola, Burkina Faso, Chad, East Timor, Ethiopia, Guinea, Liberia, Malawi, Mali, Mozambique, Niger, Nigeria, Sierra Leone, Somalia, Uganda and Zambia were supposed to get their under-5 mortality rates down from around 200 (per 1000 children born) to 70 or so, while rich countries like Japan and the U.S. needed only reduce their rates from 6 to 2 or from 11 to 4, respectively. ${ }^{38}$ So the poorest, least capable countries were assigned disproportionately large shares of the global task and the richest countries disproportionately small shares. This is an extremely unfair division of labor, made even more unbalanced by the fact that the "developed regions" were even excluded from some of the MDGs (as we have seen in the cases of the undernourishment and extreme-poverty targets). But, given that the MDGs specified no division of labor, it was easy for Western officials and media to propagate this lopsided allocation of responsibilities.

For many decades now humanity has had the capacity to eradicate undernourishment and other poverty-related deprivations. Yet poverty-related causes still account for about a third of all human deaths, and severe deprivations are still blighting the lives of humanity's poorest third, whose share of global household income has been reduced to barely $2 \%$. In human

\footnotetext{
${ }^{37}$ The recent Paris climate accord is a perfect example of this strategy of announcing ambitious wishes. Our governments agreed on a stellar proposition: that human greenhouse gas emissions would not raise the global average surface temperature more than 1.5 degrees Celsius above the pre-industrial level (we are now at +1.0 degree). In addition, each government pledged its own Intended Nationally Determined Contribution. If all governments fully live up to their pledges, the global average surface temperature will rise to exceed the preindustrial level by 2.7 degrees Celsius (http://newsroom.unfccc.int/unfccc-newsroom/indc-synthesis-report-pressrelease/, last visited May 26, 2016). Despite this obvious disconnect between their agreed wish and their individual pledges, our governments did manage to inspire widespread celebrations and complacency: phew, this problem is solved!

${ }^{38}$ National under-5 mortality rates for 1990 can be found at http://data.worldbank.org/indicator/SH.DYN. MORT?page $=5$ (last visited December 25, 2015).
} 
terms, this is a disaster of unimaginable magnitude. In economic terms, it is a minor challenge - comparable to the invasion of Iraq. ${ }^{39}$

Our response to the disastrous conditions that so many of our contemporaries are subjected to has been morally absurd: we agree that severe poverty and undernourishment should gradually shrink, hope that this will happen through economic growth with trickle-down and resort to creative accounting when increasing global inequality impedes the hoped-for progress.

To banish severe poverty and hunger from this planet, we need to recognize them as massive human rights violations that we must stop at once. We must implement institutional reforms at the national and especially the supranational level to achieve a more equitable distribution of global household income, which would ensure that even the poorest can meet their basic needs.

Open Access This article is distributed under the terms of the Creative Commons Attribution 4.0 International License (http://creativecommons.org/licenses/by/4.0/), which permits unrestricted use, distribution, and reproduction in any medium, provided you give appropriate credit to the original author(s) and the source, provide a link to the Creative Commons license, and indicate if changes were made.

\section{References}

Caulfield, Laura E., Stephanie A. Richard, Juan A. Rivera, Philip Musgrove and Robert E. Black. 2006. Stunting, Wasting, and Micronutrient Deficiency Disorders. In Disease control priorities in developing countries, ed. Dean T. Jamison et al. Washington D.C.: World Bank.

FAO (Food and Agriculture Organization of the United Nations). 1999. The state of food insecurity in the world 1999. Rome: FAO.

FAO, IFAD and WFP (Food and Agriculture Organization of the United Nations, International Fund for Agricultural Development and World Food Programme). 2015. The state of food insecurity in the world 2015. Rome: FAO.

FAO, WFP and IFAD (Food and Agriculture Organization of the United Nations, World Food Programme and International Fund for Agricultural Development). 2012. The state of food insecurity in the world 2012. Rome: FAO.

Nelson, Jane. 2002. Building partnerships. New York: United Nations Department of Public Information.

Pogge, Thomas. 2010. Politics as usual: what lies behind the pro-poor rhetoric. Cambridge: Polity Press.

Sachs, Jeffrey. 2006. The end of poverty: economic possibilities for our time. New York: Penguin Books.

Sen, Amartya. 1981. Poverty and famines. Oxford: Oxford University Press.

WHO (World Health Organization). 2008. The Global Burden of Disease: 2004 Update. Geneva: WHO Publications. Available at www.who.int/healthinfo/global_burden_disease/2004_report_update/en/index. html (last visited December 25, 2015).

World Bank. 2000. World development report 1999/2000. New York: Oxford University Press. First printing August 1999.

World Bank. 2002. Globalization, growth, and poverty. New York: Oxford University Press.

\footnotetext{
39 "The U.S. war in Iraq has cost \$ 1.7 trillion with an additional \$ 490 billion in benefits owed to war veterans, expenses that could grow to more than $\$ 6$ trillion over the next four decades counting interest, a study released on Thursday said" (http://www.reuters.com/article/us-iraq-war-anniversary-idUSBRE92D0PG20130314, last visited May 26, 2016). The cost of eradicating extreme poverty worldwide is estimated at \$ 3.5 trillion (Sachs 2006, envisioning a concerted effort over 20 years).
} 